\title{
Colorectal cancer screening with faecal immunochemical testing, sigmoidoscopy or colonoscopy: a clinical practice guideline
}

\author{
Lise M Helsingen, ${ }^{123}$ Per Olav Vandvik, ${ }^{45}$ Henriette C Jodal, ${ }^{123}$ Thomas Agoritsas, ${ }^{67}$ \\ Lyubov Lytvyn, ${ }^{7}$ Joseph C Anderson, ${ }^{8} 910$ Reto Auer, ${ }^{11} 12$ Silje Bjerkelund Murphy, ${ }^{13}$ \\ Majid Abdulrahman Almadi, ${ }^{14}{ }^{15}$ Douglas A Corley, ${ }^{16}{ }^{17}$ Casey Quinlan, ${ }^{18} 1920$ Jonathan M Fuchs, ${ }^{21}$ \\ Annette McKinnon, ${ }^{22}$ Amir Qaseem, ${ }^{23}$ Anja Fog Heen, ${ }^{24}$ Reed A C Siemieniuk, ${ }^{7}$ Mette Kalager, ${ }^{12} 3$ \\ Juliet A Usher-Smith, ${ }^{25}$ Iris Lansdorp-Vogelaar, ${ }^{26}$ Michael Bretthauer, ${ }^{23}{ }^{3}$ Gordon Guyatt ${ }^{7}$
}

Full author details can be found at the end of the article

Correspondence to : L M Helsingen lisemhe@medisin.uio.no

Cite this as: BMJ 2019;367:15515 doi: 10.1136/bmj.15515

This BM/ Rapid Recommendation article is one of a series that provides clinicians with trustworthy recommendations for potentially practice changing evidence. BMJ Rapid Recommendations represent a collaborative effort between the MAGIC group (http:// magicproject.org/) and The $B M J$. A summary is offered here and the full version including decision aids is on the MAGICapp (https://app.magicapp.org), for all devices in multilayered formats. Those reading and using these recommendations should consider individual patient circumstances, and their values and preferences and may want to use consultation decision aids in MAGICapp to facilitate shared decision making with patients. We encourage adaptation and contextualisation of our recommendations to local or other contexts. Those considering use or adaptation of content may go to MAGICapp to link or extract its content or contact The BM/ for permission to reuse content in this article.

\section{ABSTRACT}

Clinical question Recent 15-year updates of sigmoidoscopy screening trials provide new evidence on the effectiveness of colorectal cancer screening. Prompted by the new evidence, we asked: "Does colorectal cancer screening make an important difference to health outcomes in individuals initiating screening at age 50 to 79 ? And which screening option is best?"

Current practice Numerous guidelines recommend screening, but vary on recommended test, age and screening frequency. This guideline looks at the evidence and makes recommendations on screening for four screening options: faecal immunochemical test (FIT) every year, FIT every two years, a single sigmoidoscopy, or a single colonoscopy.

Recommendations These recommendations apply to adults aged 50-79 years with no prior screening, no symptoms of colorectal cancer, and a life expectancy of at least 15 years. For individuals with an estimated 15 -year colorectal cancer risk below $3 \%$, we suggest no screening (weak recommendation). For individuals with an estimated 15 -year risk above 3\%, we suggest screening with one of the four screening options: FIT every year, FIT every two years, a single sigmoidoscopy, or a single colonoscopy (weak recommendation). With our guidance we publish the linked research, a graphic of the absolute harms and benefits, a clear description of how we reached ourvalue judgments, and linked decision aids.

How this guideline was created A guideline panel including patients, clinicians, content experts and methodologists produced these recommendations using GRADE and in adherence with standards for trustworthy guidelines. A linked systematic review of colorectal cancer screening trials and microsimulation modelling were performed to inform the panel of 15-year screening benefits and harms. The panel also reviewed each screening option's practical issues and burdens. Based on their own experience, the panel estimated the magnitude of benefit typical members of the population would value to opt for screening and used the benefit thresholds to inform their recommendations.

The evidence Overall there was substantial uncertainty (low certainty evidence) regarding the 15 -year benefits, burdens and harms of screening. Best estimates suggested that all four screening options resulted in similar colorectal cancer mortality reductions. FIT every two years may have little or no effect on cancer incidence over 15 years, while FIT every year, sigmoidoscopy, and colonoscopy may reduce cancer incidence, although for FIT the incidence reduction is small compared with sigmoidoscopy and colonoscopy. Screening related serious gastrointestinal and cardiovascular adverse events are rare. The magnitude of the benefits is dependent on the individual risk, while harms and burdens are less strongly associated with cancer risk.

Understanding the recommendation Based on benefits, harms, and burdens of screening, the panel inferred that most informed individuals with a 15 -year risk of colorectal cancer of $3 \%$ or higher are likely to choose screening, and most individuals with a risk of below $3 \%$ are likely to decline screening. Given varying values and preferences, optimal care will require shared decision making. 


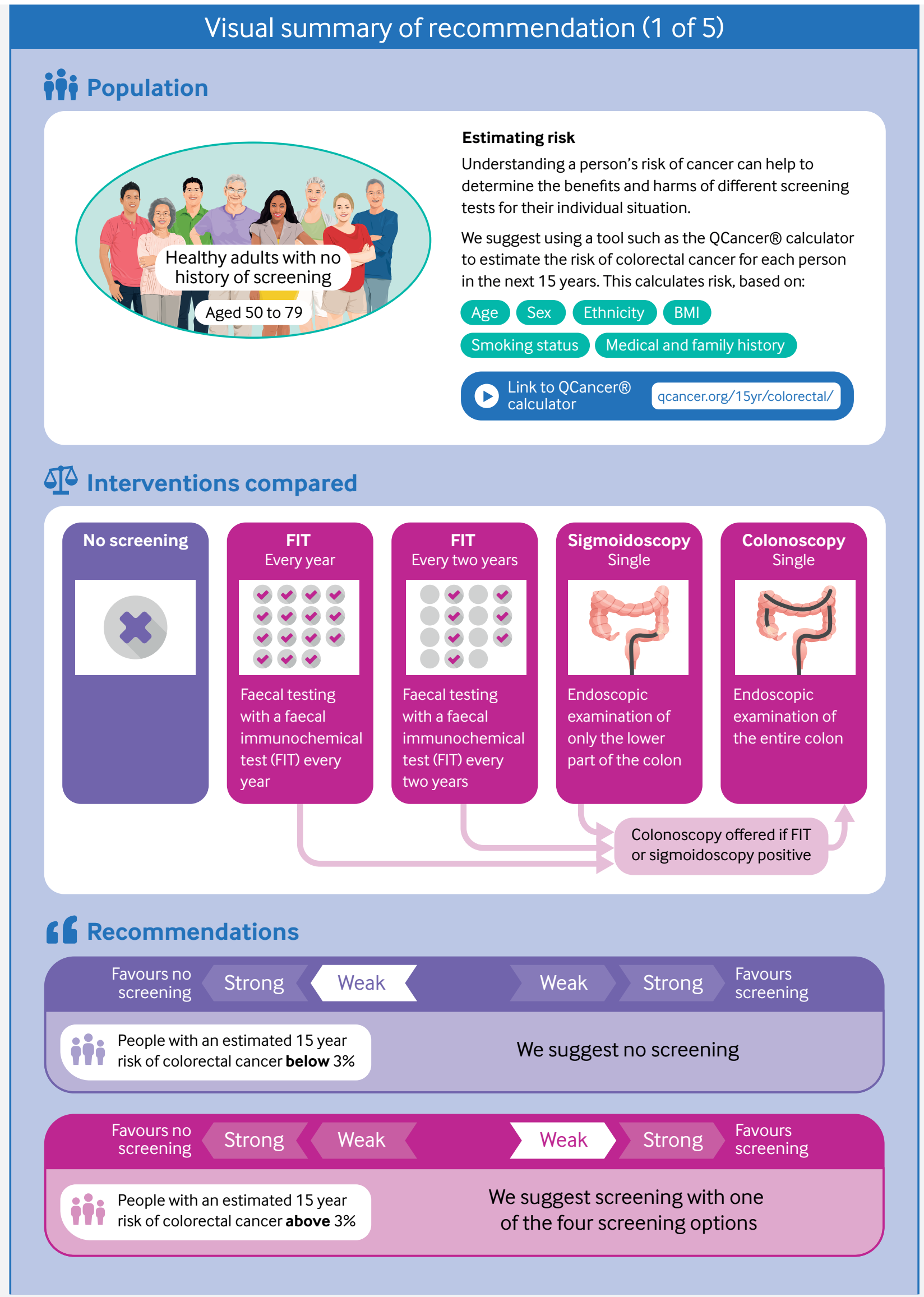

Disclaimer: This infographic is not a clinical decision aid. This information is provided without any representations, conditions or warranties that it is accurate or up to date. BMJ and its licensors assume no responsibility for any aspect of treatment administered with the aid of this information. Any reliance placed on this information is strictly at the user's own risk. For the full disclaimer wording see BMJ's terms and conditions: http://www.bmj.com/company/legal-information/ 


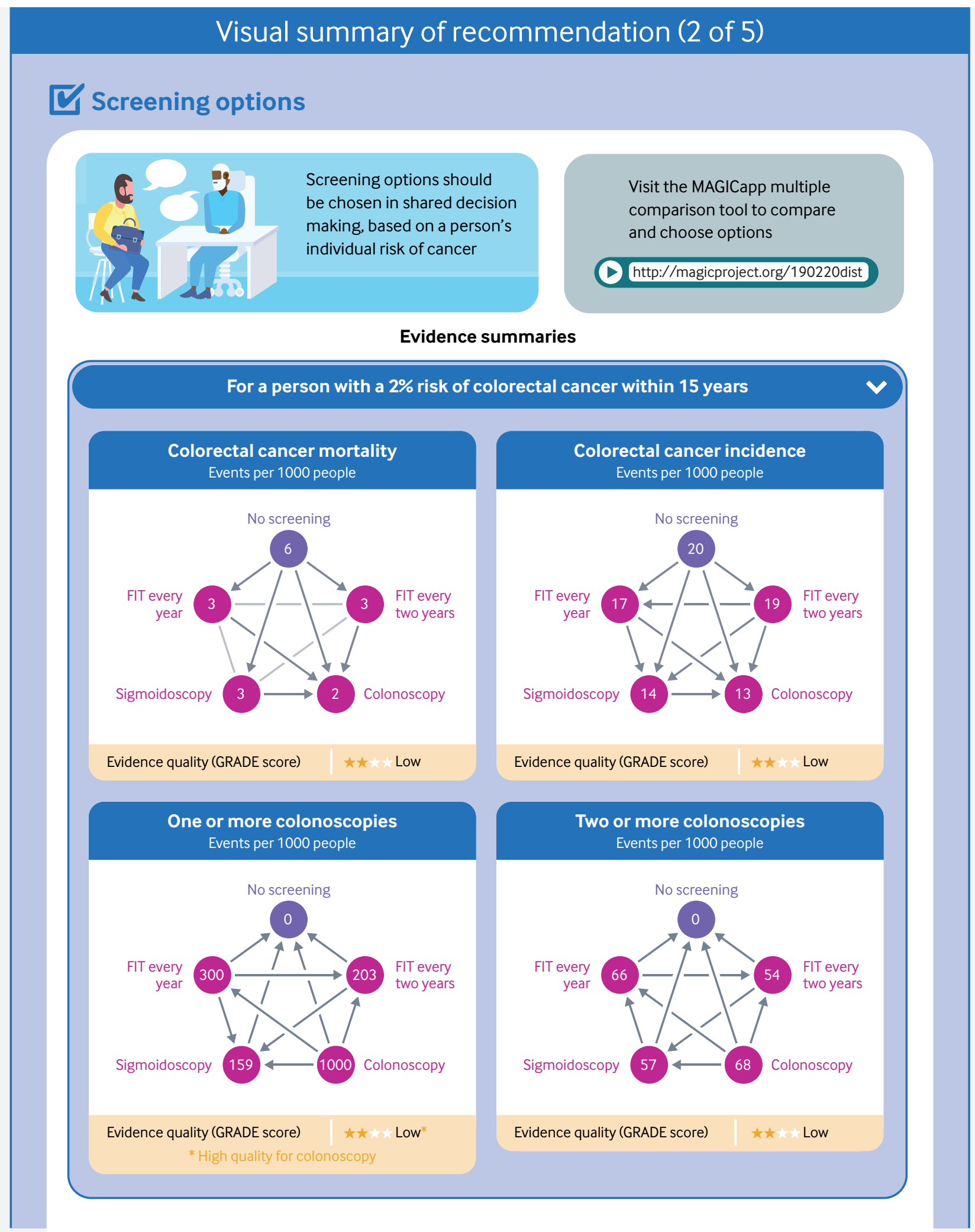




\section{Visual summary of recommendation (3 of 5)}

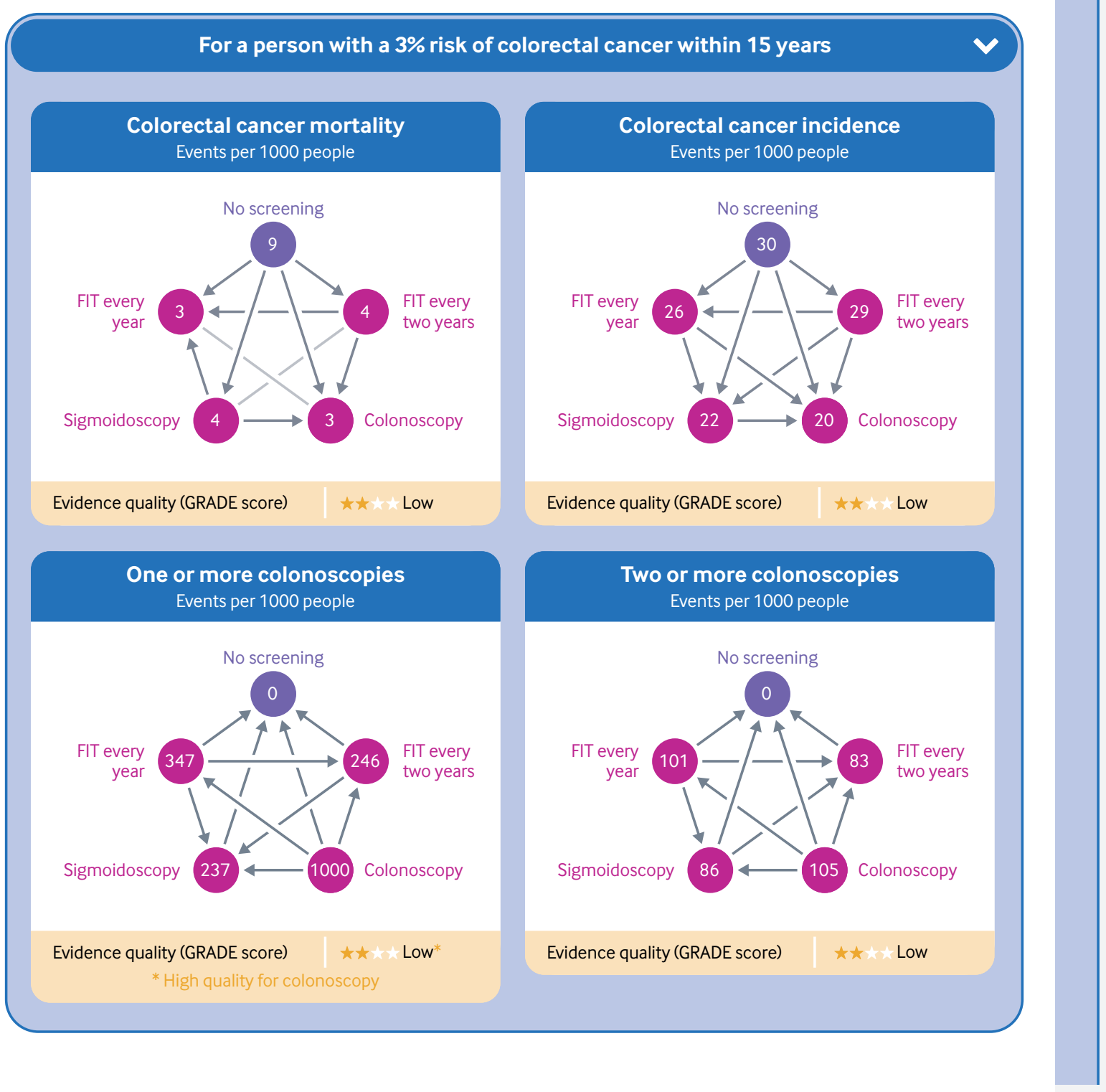




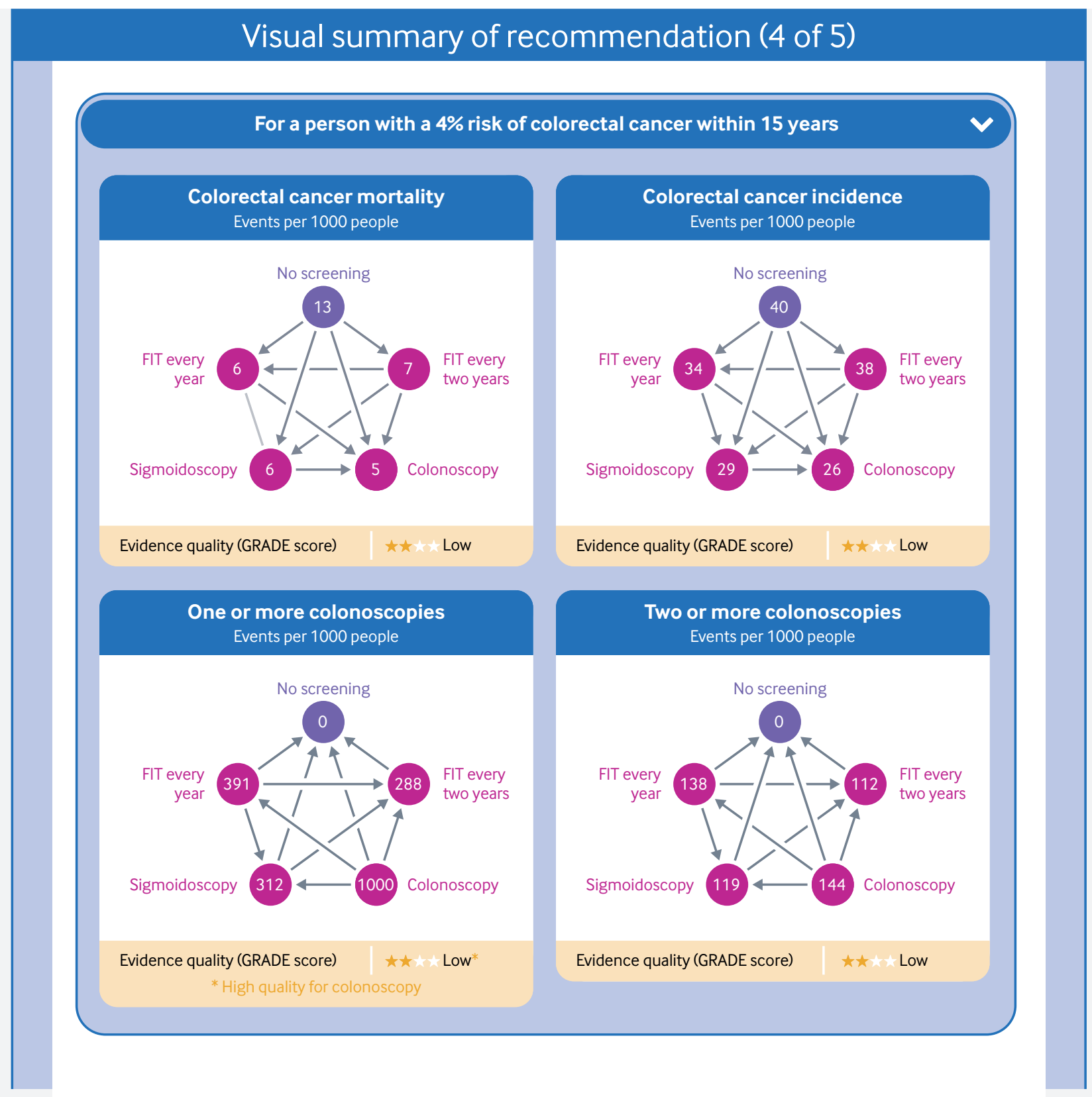




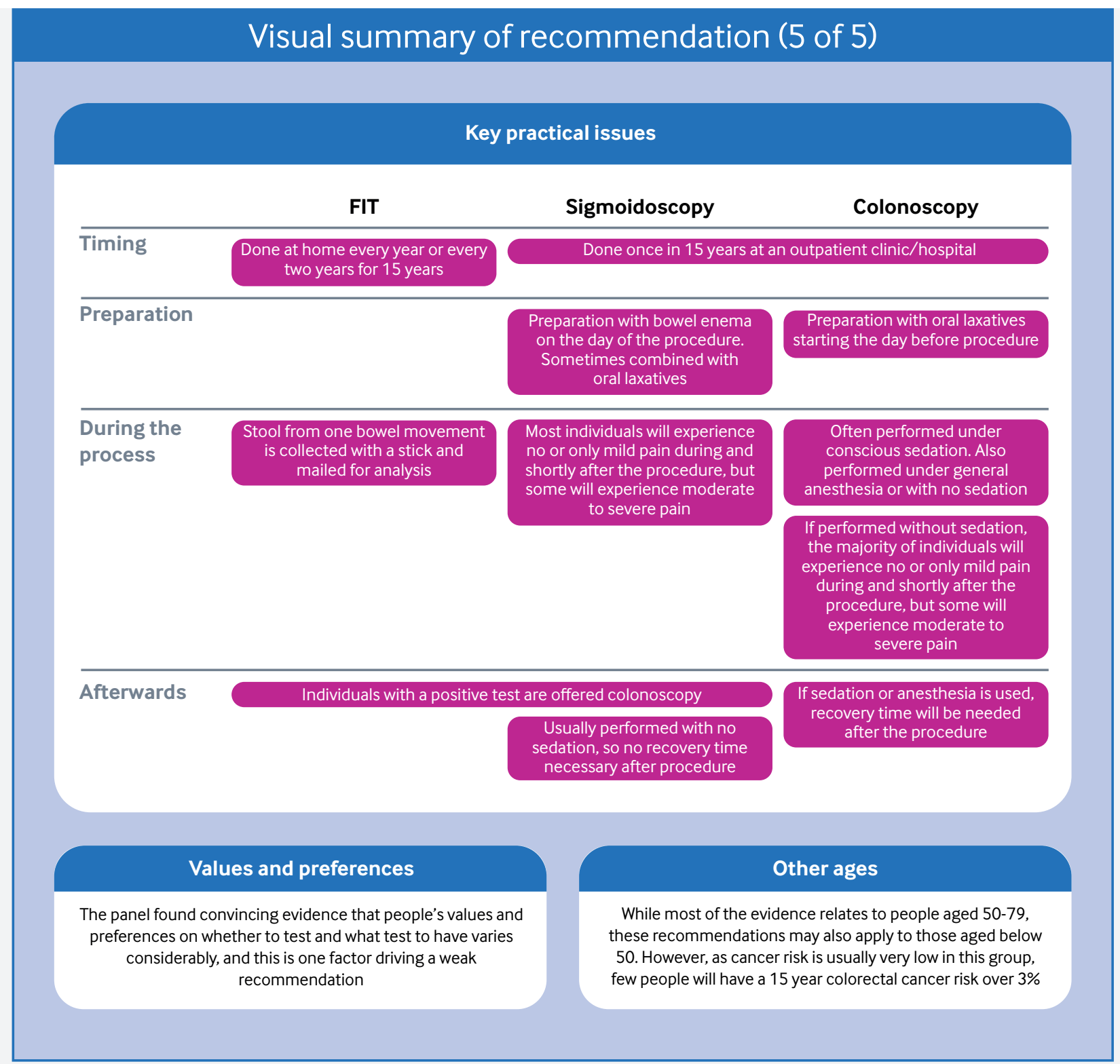

\section{thebmj See an interactive version http://bit.ly/BMJrrCRC}


What is the role of colorectal cancer screening with faecal immunochemical testing (FIT), flexible sigmoidoscopy or colonoscopy for people aged 50 to 79 years?

Recent updates to three of the major trials on sigmoidoscopy screening were published in 2017-19. ${ }^{1-3}$ The trials provide evidence on screening effectiveness for up to 15 years after a single sigmoidoscopy. Two of these trials reported a reduction in colorectal cancer mortality and incidence with sigmoidoscopy screening in men, but only a small or no reduction in women. ${ }^{23}$ This has sparked interest in whether women and men should be screened differently, and in which test is better for screening for colorectal cancer. We concluded that this new evidence could change current recommendations. Our recommendations are based on systematic reviews of benefits and harms of screening and, in the absence of randomised trial results for FIT and colonoscopy, on microsimulation modelling. ${ }^{45}$

The lifetime risk of colorectal cancer is approximately $5 \%$ in many Western countries, with varying risk in different geographical areas. ${ }^{6}$ It is one of the most common cancers in both men and women. An individual's risk of cancer depends on age, sex, and genetics, and may be influenced by lifestyle factors such as alcohol intake, smoking, physical activity, and diet. ${ }^{7}$ The five-year survival of colorectal cancer is $65 \%$, with higher survival

\section{HOW THESE RECOMMENDATIONS WERE CREATED}

Our international panel included patient partners (individuals with experience of colorectal cancer screening), general practitioners, general internists, gastroenterologists, content experts (those conducting primary studies in colorectal cancer screening and immersed in the field), methodologists, and a nurse practitioner. No panel member reported financial conflicts of interest. Intellectual and professional conflicts were minimised and managed (see appendix 2 for details of panel members and their competing interests). The panel initially decided on the scope of the recommendation and the outcomes that they considered most important for individuals considering screening.

It was out of the scope for these guidelines to address all existing screening options. The panel decided to include the most commonly used options with the most solid evidence base. Randomised trials with sufficient follow-up for estimation of screening benefits have studied only sigmoidoscopy and guaiac faecal occult blood testing (gFOBT). However, today the most widely practiced screening tests are faecal immunochemical test (FIT) and colonoscopy. ${ }^{89}$ FIT has a higher sensitivity and is more acceptable than gFOBT, and most screening programmes using faecal blood testing have changed to FIT. The panel therefore chose not to include guidance on gFOBT. ${ }^{1617}$ The panel requested the best evidence for four screening options: FIT every year, FIT every two years, a single sigmoidoscopy, and a single colonoscopy. For each option, the panel chose a 15-year time frame because that corresponds to the longest follow-up in the existing randomised sigmoidoscopy screening trials. FIT tests with a cut-off of $20 \mu \mathrm{g} \mathrm{Hb} / \mathrm{g}$ faeces were considered positive.

The panel identified the following important outcomes: all-cause mortality, colorectal cancer mortality, colorectal cancer incidence, colorectal bleeding and perforation, other serious adverse events, and number of individuals needing at least one, two, or more colonoscopies. The panel also identified the following practical issues that could influence decisions regarding screening: emotional stress and anxiety related to a positive test, pain, discomfort, and absence from work related to screening procedures.
To inform the recommendations, the panel asked the following questions:

1. What benefit (reduced colorectal cancer mortality or incidence) would most individuals require to undergo colorectal cancer screening? In other words, what are peoples' anticipated values and preferences in trading off benefits versus burdens and harms?

2. In healthy individuals aged 50-79 years, what are the benefits, harms, and burdens over a 15 year period of screening with faecal testing every year or every two years, or a single sigmoidoscopy or colonoscopy, compared with no screening or with one another?

Parallel teams conducted systematic reviews and microsimulation modelling to inform the panel (described in detail in appendices 3-5 and the linked articles ${ }^{45}$ ).

The systematic review of values and preferences did not provide clear evidence of what benefit most individuals would require to undergo screening. The panel therefore identified thresholds for anticipated magnitude of benefit people would require and used this as guidance when deciding on the recommendations (see box 2 and appendix 3 for details).

A dedicated team performed a systematic review and network meta-analysis of randomised trials evaluating benefits and harms of colorectal cancer screening (see linked article ${ }^{5}$ ).

No randomised trials have addressed the effectiveness of FIT and colonoscopy screening, so the panel requested microsimulation modelling to estimate the benefits, burdens, and harms of the four screening options compared with no screening over a 15 year period (see linked article ${ }^{4}$ ). The panel also requested a systematic survey of reviews of screening-related burdens and harms that included observational studies designed to evaluate harms after screening, because data from randomised trials were limited (see appendix 4).

The panel asked the teams to explore potential subgroup effects for screening benefits by sex and of screening-related harms by age.

The panel acknowledged that the risk of cancer, and thus the magnitude of expected benefits and harms, varies substantially in the target population for these recommendations. The panel decided to base the recommendation on an individual estimation of colorectal cancer risk over 15 years. Details about the choice of calculator for the prediction of individual risk is provided in appendix 6.

The panel found that the thresholds of required benefit for either colorectal cancer mortality or incidence met at approximately $3 \%$ risk for all screening options.

Figure 1 shows the benefits of the different screening tests per 1000 screened, depending on the 15-year risk of colorectal cancer.

The panel followed BMJ Rapid recommendations procedures for creating a trustworthy recommendation, including the GRADE approach (see appendix 7). The panel met by videoconferences to discuss the evidence and formulate recommendations, ${ }^{1819}$ and considered the balance of benefits, harms, and burdens of the screening options and no screening, the certainty of the evidence for each outcome, expected variations in individuals' values and preferences, as well as practical issues. ${ }^{20}$ Recommendations using GRADE can be strong or weak, for or against a course of action. ${ }^{18}$ The panel made the recommendation from an individual perspective, assuming that all options were available and affordable. The recommendation does not take a public health, societal, or health payer perspective. Healthcare systems can adapt these recommendations by including costs and other key issues of relevance, contextualised to national and local circumstances. ${ }^{21}$

The number of individuals in need of two or more colonoscopies presented in this guidance differ slightly from the numbers presented to the panel in the process of making the recommendations (see appendix 3 ). The difference was due to a coding mistake that has been corrected. The panel decided that these changes did not alter the final recommendations.

One of the content experts on the panel did not wish to be a co-author of this article due to disagreement with the approach and the final recommendations. Two panel members (ILV and $\mathrm{DAC}$ ) has strong reservations concerning the use of thresholds for the recommendations, due to limitations in the way the thresholds were determined. Box 2 presents the process of developing the thresholds and its limitations. 
Table 1 Major guideline recommendations addressing colorectal cancer screening for average risk populations; all recommend screening from a certain age, and some recommend against screening in older age; none explicitly incorporates shared decision making based on individual risk and perceived benefits, harms, and burdens. For simplicity, the table includes only the preferred test or first-tier recommendations

Organisation Screening age GRADE strength of recommendation Recommended test and timing

Screening for 50-75 years N/A High sensitivity gFOBT or FIT every year

Not recommended 775 years $\quad$ gFOBT or FIT every 3 years or

Sigmoidoscopy every 5 years

Colonoscopy every 10 years

US Preventive Services Task Force, $2016 \quad$ Screening for $50-75$ years

$\mathrm{N} / \mathrm{A}$

gFOBT or FIT everyyear

For $76-85$ years, an individual

decision

National Comprehensive Cancer Network

Screening for $50-75$ years

N/A

Guidelines, 2017

For $76-85$ years, an individual

decision

FIT-DNA every 1-3 years

FIT everyyear or

Sigmoidoscopy every 10 years

Sigmoidoscopy every 5 years

Colonoscopy every 10 years

CT colonography every 5 years

United States Multi-Society Task Force of Colorectal

Screening for age $50-75$ years For 76-85 years, consider for those without prior screening

American Cancer Society, 2018

Screening from 45 years

Screening for $50-75$ years

For 76-85 years an individual

decision based on preference,

life expectancy, and overall

Colonoscopy every 10 years

health

gFOBT or FIT everyyear

Faecal DNA test every 3 years

Sigmoidoscopy every 5 - 10 years \pm gFOBT or FIT every 3 years

CT colonography every 5 years

For screening: strong for 50-75, weak for 76-85 FIT every year

years Colonoscopy every 10 years

For screening: weak for 45-49, strong for 50-75, High sensitivity gFOBT or FIT every year

weak for 76-85 years Multi-targeted stool DNA every 3 years

Colonoscopy every 10 years

CT colonography every 5 years

Sigmoidoscopy every 5 years

Canadian Task Force on Preventive Health Care, Screening for 50-74 years $\quad$ For screening: weak for 50-59, strong for 60-74 gFOBT or FIT every 2 years

2016

Notrecommended for $>75$

Weak against screening $>75$ years

Sigmoidoscopy every 10 years

German Guideline Program in Oncology, 2019

Start 50 years

N/A Colonoscopy every 10 years

Spanish Society of Medical Oncology, $2014 \quad$ Screening for $50-74$ years N/A

FIT every two years

gFOBT every $1-2$ years

Sigmoidoscopy every 5 years

Colonoscopy every 10 years

National screening programmes in Sweden, New Screening for 60-74 years N/A FIT every 2 years

Zealand and United Kingdomt

National screening programmes in Denmark and Screening for $50-74$ years N N/A FIT every 2 years

France

Korean Guidelines for Colorectal Cancer Screening Start 50 years Strong, for screening Colonoscopy every 5 years

and Polyp Detection, 2012

\begin{tabular}{llll}
\hline Chinese Society of Gastroenterology, 2014 & Screening for 50-74 years & N/A & FIT and questionnaire every 3 years \\
\hline Updated Asia Pacific Consensus Recommendations & Screening for 50-75 years & N/A & FIT, interval not mentioned
\end{tabular}

on colorectal cancer screening, 2015

National Guidelines for Colorectal Cancer Screening Screening for 45-70 years Strong, for screening 54-70 Colonoscopy every 10 years

in Saudi Arabia, $2015 \quad$ Not recommended $>70$ years Weak against screening $>70$ years

World Gastroenterology Organisation, $2007 \quad$ Start 50 years $\quad$ N/A

NHMRC, Clinical Guidelines for Prevention, Early Screening for $50-74$ years N/A

Detection and Management of Colorectal Cancer

Australia, 2017

National guideline in Japan Start 40 years

gFOBT = guaiac faecal occult blood test. FIT = faecal immunochemical test.

The recommendations listed is a selection of recommendations identified through two systematic surveys: one found 15 colorectal cancer screening guidelines published in English between 2007 and 2017 ( 6

from North America, 4 from Europe, 5 from Asia) ${ }^{8}$; the other survey in high income countries found another 19 guidelines.

*Update of guideline in progress (Amir Qaseem, ACP, personal communication).

tIn addition to FIT screening every two years, a one-time sigmoidoscopy is currently being rolled out for people at age 55 in the UK. ${ }^{10}$

observed in localised disease. All patients with colorectal cancer are offered surgical treatment. In addition, patients with advanced disease undergo chemotherapy or radiation.

Screening aims at reducing colorectal cancer mortality and/or incidence by detecting cancer early (by regular testing for faecal blood), or prevention of cancer development (by detecting and removing cancer precursors, adenomas). The awareness of colorectal cancer screening has increased from the early 2000s, and most European countries, North America, and parts of South America, Asia, and Oceania have implemented or are planning implementation of screening (table 1$){ }^{11}$

This guideline provides recommendations for the most widely used screening tests worldwide. It is the first guideline on colorectal cancer screening to provide 
Box 1 | Linked resources for this BMJ Rapid Recommendations cluster

- Helsingen LM, Vandvik PO, Jodal HC, et al. Colorectal cancer screening with faecal immunochemical testing, sigmoidoscopy or colonoscopy: a clinical practice guideline. BMJ 2019;367:15515.

- Summary of the results from the Rapid Recommendation process

- Jodal HC, Helsingen LM, Anderson JC, et al. Colorectal cancer screening with faecal testing, sigmoidoscopy or colonoscopy: a systematic review and network metaanalysis. BMJ Open 2019;0:e032773. ${ }^{5}$

- Review of all available trials that assessed colorectal cancer screening

- Buskermolen M, Cenin DR, Helsingen LM, et al. Colorectal cancer screening with faecal immunochemical testing, sigmoidoscopy or colonoscopy: a microsimulation modelling study. BMJ 2019;367:15383. ${ }^{4}$

- Modelling study of different modalities for colorectal cancer screening

- MAGICApp (https://app.magicapp.org/public/guideline/ EQNVKj)

-Expanded version of the results with multilayered recommendations, evidence summaries, and decision aids for use on all devices

explicit judgments of values and preferences, and basing the recommendations on absolute benefits, harms, and burdens of screening in a 15 year period. Within the population under consideration for this guideline, there are groups with different risks of developing colorectal cancer, ranging from less than $1 \%$ to more than $15 \%$ over 15 years. Most people, however, will be in the range from $1 \%$ to $7 \%$. This is the first guideline that gives recommendations based on individual cancer risk. The guideline also includes practical issues important for the screening decision and decision aids for use in the clinical encounter.

The main infographic provides an overview of modelled estimates of the absolute benefits and harms of screening, when the 15-year risk of colorectal cancer is $2 \%, 3 \%$, or $4 \%$, and assuming $100 \%$ adherence to all screening tests, work-up, and surveillance colonoscopies in a 15 year period. A microsimulation model informed by randomised trials and observational studies provided all estimates of benefit and harm. ${ }^{4}$ Box 1 shows all evidence linked in this Rapid Recommendation package. Table 2 shows any new evidence that has emerged after initial publication of these recommendations.

\section{Current practice}

What is recommended?

Some countries have systematic, population based, screening programmes in which presumed asymptomatic people are invited for screening. In others, including the US, widespread opportunistic screening is common (depending on initiatives from patients or clinicians), although in some settings there are comprehensive screening outreach programmes, such as within the Kaiser Permanente health system. ${ }^{12}$

Most guidelines recommend screening starting at age 50 years, when the risk of cancer in the next 15 years is typically 1-2\% (in European and North American populations). ${ }^{13-15}$ Screening is performed with many different tests and combination of tests, with different frequencies and in different age groups. However, the most common screening options are faecal testing, sigmoidoscopy, and colonoscopy. Which test is used varies due to different priorities and different interpretation of the existing evidence by guideline developers and screening providers, but also because of differences in peoples' values and preferences.

Current guidelines provide the same recommendations for all individuals above a certain age and do not account for individual differences in cancer risk. Table 1 presents a summary of some of these recommendations based on two surveys published in 2018. ${ }^{89}$

\section{The evidence}

Evidence summaries are available for those at 2\%, 3\%, and $4 \%$ risk at the start of their screening (see main infographic). Fig 2 provides an overview of the data sources used to inform this guideline.

\section{How do people value colorectal cancer screening?}

People's view on the net benefit of screening varies substantially. ${ }^{2223}$ We know this because our literature review found a variety of different recommendations (see table 1), limited uptake of screening in practice (see box 2 ) and variation in studies of people's values and preferences.

The literature review of studies on values and preferences did not identify evidence informing the magnitude of benefit people would require to undergo colorectal cancer screening. Therefore, before reviewing the evidence of screening benefits, the panel used their own experience to hypothesise what benefit of screening they thought people would require to undergo screening. This process helped minimise the influence of prior guideline recommendations, or potential preconceived beliefs of the net benefit of screening, on the panelists' view on the threshold of required benefits. (See box 3 and appendix 3 for details on this process).

Panel members' views varied, but, after discussion, we decided to use the following thresholds of benefits, at which the panel believed around half of informed individuals would choose screening:

- Sigmoidoscopy or colonoscopy if the screening could reduce colorectal cancer mortality and/or incidence by 10 or more per 1000 screened over a 15 year period

- FIT if the screening could reduce colorectal cancer mortality and/or incidence by 5 or more per 1000 screened over a 15 year period. (Lower threshold because the panel perceived the burdens of testing as smaller for FIT than for sigmoidoscopy or colonoscopy.)

What are the benefits of colorectal cancer screening? Randomised trials have addressed screening with sig moidoscopy and gFOBT and provide high to moderate certainty evidence for screening effectiveness: sigmoidoscopy reduces colorectal cancer mortality and incidence after 15 years of follow-up, and gFOBT every year or every 
A Cancer deaths prevented

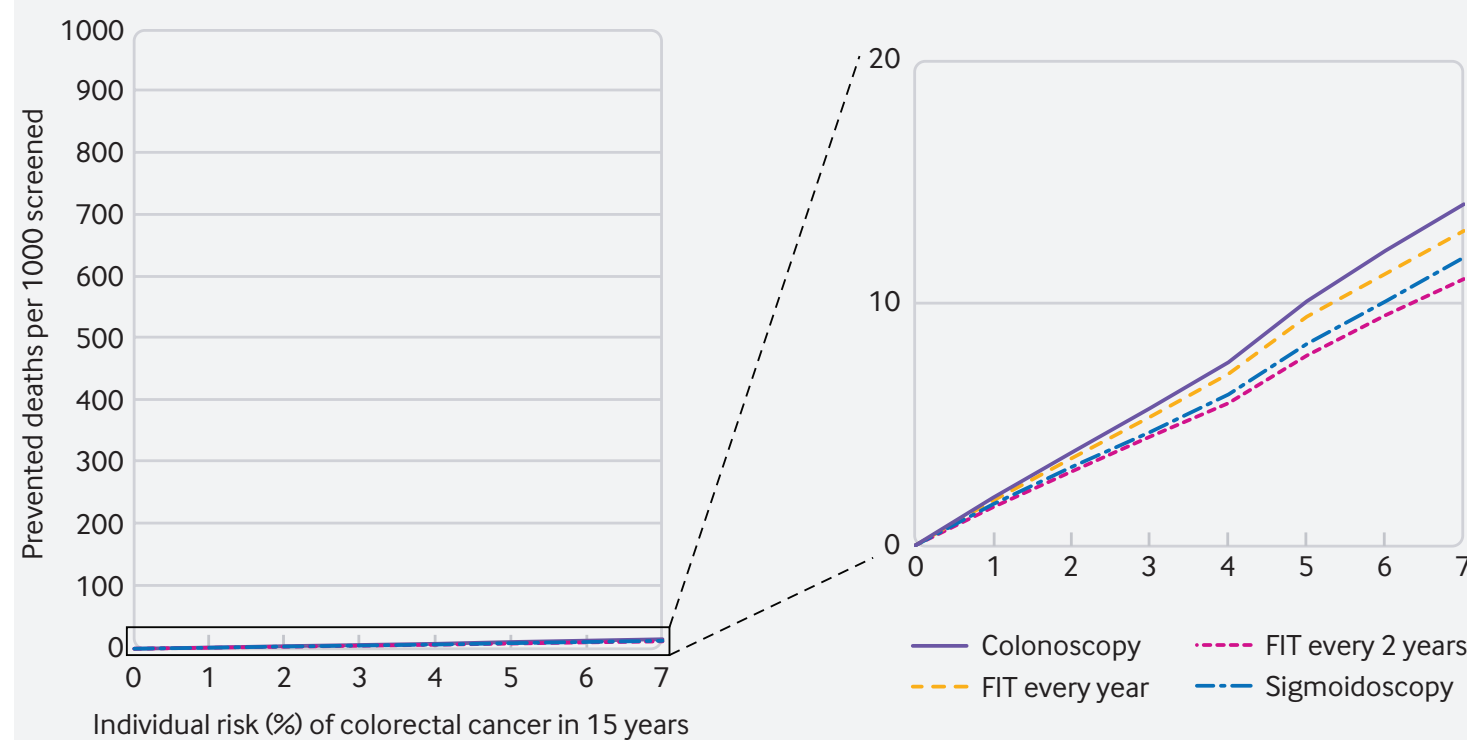

B Cancer cases prevented

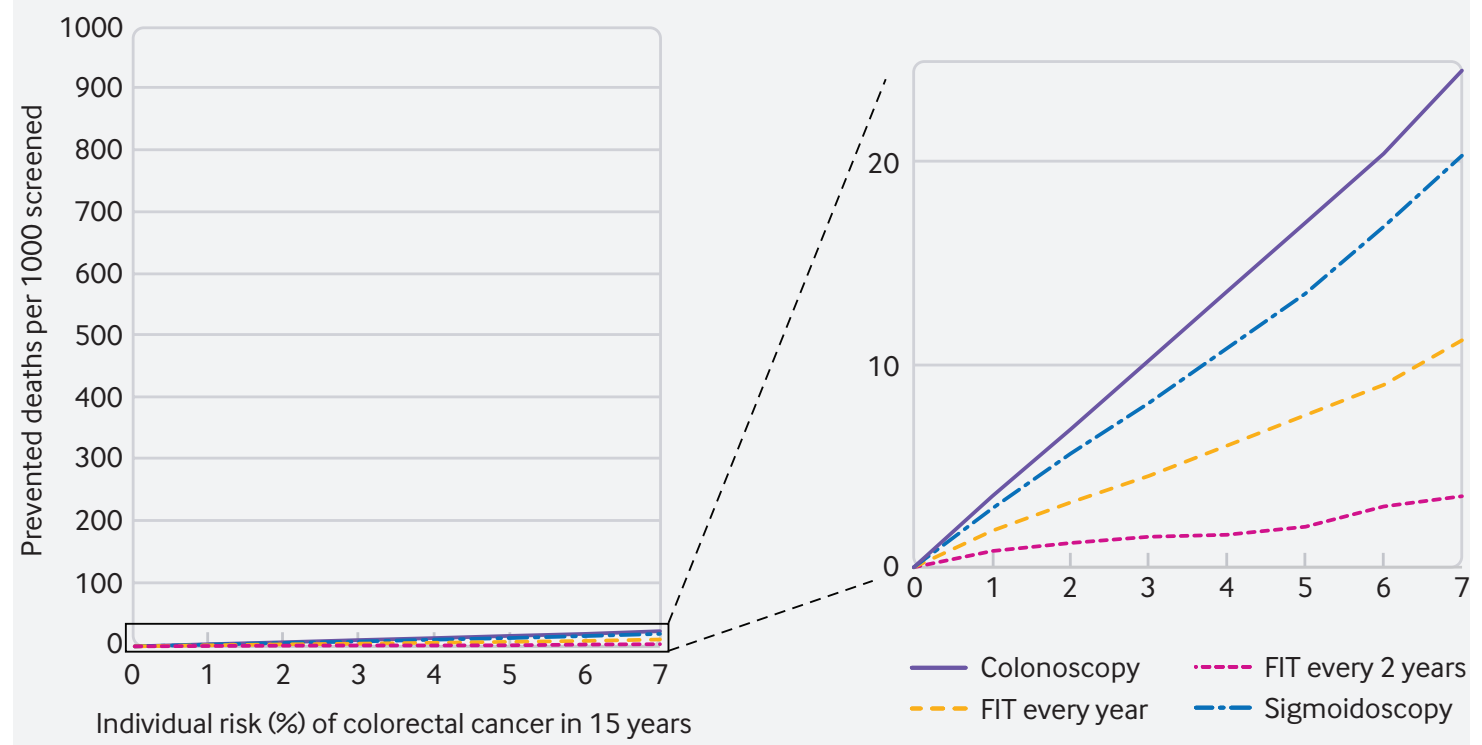

Fig 1| Number of colorectal cancer (a) deaths and (b) cases prevented by different screening options per 1000 screened individuals, stratified by individuals' 15 -year risk of colorectal cancer.

two years reduces colorectal cancer mortality but has little or no impact on cancer incidence. Neither sigmoidoscopy nor gFOBT affects all-cause mortality. For details, see the linked review. ${ }^{5}$

Because of lack of trial data for FIT and colonoscopy, we used a microsimulation model to provide ultimate estimates for clinical decision making. The model has been validated against the results from the trials of sigmoidoscopy and gFOBT, but due to the assumptions inherent in the model, it can only provide estimates of low certainty. The estimates of colorectal cancer incidence and mortality reduction from the model are higher than those observed in randomised screening trials. Our model is based on $100 \%$ adherence to screening, work-up and surveillance colonoscopies, whereas the trial estimates reflect substantially lower rates of adherence (see box 2). A linked article provides details of the modelling. ${ }^{4}$

All the modelling data are of low certainty. It is a useful indication, but there is a high chance that new evidence will show a smaller or larger benefit, which in turn may alter these recommendations. Compared with no screening, the model estimates that:

- Colorectal cancer mortality may be reduced similarly by all four screening tests

- FIT every two years (relative risk 0.5)

- FIT every year (relative risk 0.41)

- Single sigmoidoscopy (relative risk 0.48)

- Single colonoscopy (relative risk 0.37) 


\section{DATA SOURCES}

Use this information to gauge how similar your patients' conditions are to those of people included in the evidence base for these recommendations

\section{$\square$ Number of trials}
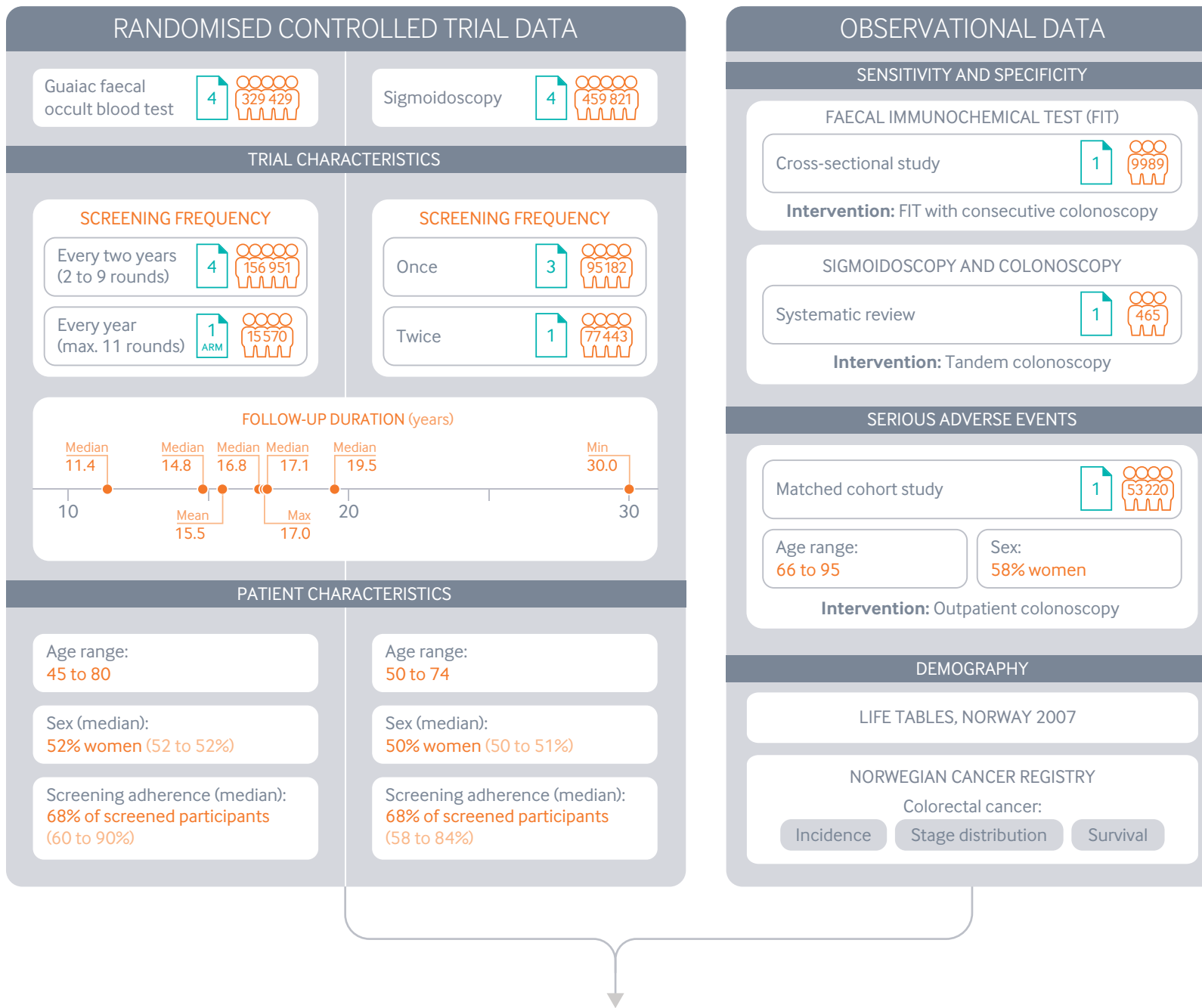

Intervention: FIT with consecutive colonoscopy

SIGMOIDOSCOPY AND COLONOSCOPY

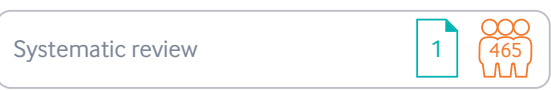

Intervention: Tandem colonoscopy

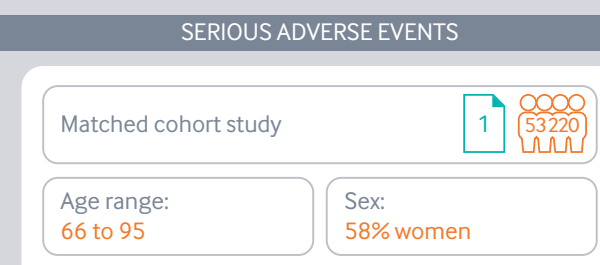

Intervention: Outpatient colonoscopy

DEMOGRAPHY

LIFE TABLES, NORWAY 2007

NORWEGIAN CANCER REGISTRY

Colorectal cancer:

Incidence Stage distribution Survival
MODELLING: 15-YEAR PREDICTIONS

KEY ASSUMPTIONS

Natural history of adenoma and preclinical cancer development. Calibrated to observational data and trial data

Adherence to
screening and follow-up

SCREENING OPTIONS

$\begin{array}{ll}\text { Age } & 50 \text { to } 79 \text { years } \\ \text { range }\end{array}$ Timeframe 15 years

Interventions

FIT every two years FIT every year

Sigmoidoscopy once Colonoscopy once
BENEFITS REQUIRED

828. Estimated by guideline panel

FIT EVERY YEAR OR EVERY TWO YEARS Colorectal cancer mortality and/or incidence reduction of 5 per 1000 screened $(0.5 \%)$

SIGMOIDOSCOPY OR COLONOSCOPY Colorectal cancer mortality and/or incidence reduction of 10 per 1000 screened (1\%)

Fig 2| Data sources included in the modelling study of the absolute benefits and harms of different colorectal cancer screening options. 


\section{Box 2 Screening uptake}

Participation in systematic screening is often under $50 \%$, but varies widely:

- In screening programmes with faecal testing in Australia, Europe, America, and Asia, the participation rate varied between $16 \%$ and $68 \% .{ }^{11}$

- In a European, population based, randomised trial of colonoscopy screening, participation rates were $61 \%$ in Norway, $40 \%$ in Sweden, 33\% in Poland, and 23\% in the Netherlands. ${ }^{24}$

- In another randomised trial comparing faecal immunochemical test (FIT) and colonoscopy in Spain, the rate of participation was higher in the FIT group (after one round) than in the colonoscopy group (34\% v $25 \%$ ). ${ }^{25}$

- Some organised efforts that incorporate screening outreach and follow-up have demonstrated screening rates of over $80 \% .^{12}$

- Colorectal cancer incidence

- May be reduced little or not at all by FIT every two years (relative risk 0.95)

- FIT every year may achieve a small reduction (relative risk 0.85)

- May be reduced by a single sigmoidoscopy (relative risk 0.73)

- May be reduced by a single colonoscopy (relative risk 0.66).

There was no clinically relevant difference in all-cause mortality when comparing screening with no screening, or between the different screening options. ${ }^{4}$

\section{Do the benefits differ by sex?}

Based on the meta-analysis of randomised trial data, the panel believed the subgroup effect that sigmoidoscopy screening is more effective in men than women. ${ }^{5}$ They used criteria for credibility of subgroup effects to judge this. ${ }^{26}$ However, the relative effect differences of screening in men and women did not translate into an absolute difference to justify different recommendations for the sexes. Appendix 4 presents this evidence and a worked example.

\section{Where did data on burdens and harms of screening and follow-up come from?}

Number of colonoscopies needed was considered an important burden of screening by the panel. Colonoscopies are performed either as the primary screening test, after a positive sigmoidoscopy or FIT screening, or as surveillance due to the finding of adenomas. No trial provides estimates of the number of individuals requiring colonoscopies after screening over a 15 year period. Our estimates are derived from the microsimulation model and are of low certainty. The model assigns every individual with a high risk adenoma (several adenomas or an adenomas $>10 \mathrm{~mm}$ diameter) to surveillance colonoscopy after three years, and thereafter repeated colonoscopies with intervals of three to five years (depending on the findings).

The 15-year estimates for screening related mortality, risk of colorectal perforations and bleedings, other gastrointestinal adverse events, and cardiovascular adverse events are derived from additional modelling of a large
Box $3 \mid$ Process and limitations of determining thresholds of benefits required to undergo screening

\section{Process of determining a benefit threshold}

The panel completed three surveys presenting different hypothetical screening scenarios. For each scenario, the panelists chose whether: almost all ( $>90 \%)$, most (75-90\%), or the majority (50-75\%) would choose or decline screening. The panelists responded according to their estimates of what most well informed people would choose (see appendix 3 for more details of this process).

- The first survey included hypothetical scenarios of colonoscopy screening with varying absolute risk reductions for colorectal cancer mortality $(1,10,20$, and 30 per 1000 screened) over a 15 year period.

- The second survey focused on what benefit would be required to recommend one screening test over another.

- Initially, the panel chose the same benefit threshold for all tests. However, after reviewing the full evidence summaries (see main infographic), the panel felt that the burdens and harms of FIT were considerably smaller than for sigmoidoscopy or colonoscopy. The panel decided to undertake a third survey presenting scenarios of FIT screening with reductions in colorectal cancer mortality ranging from 1 to 10 per 1000 screened.

\section{Limitations}

There are several limitations related to the establishment of these thresholds

- First, because no direct evidence has addressed how much benefit people would require to be willing to undergo screening, the panel relied on indirect evidence and their experience in making their estimates.

- Second, the way the evidence is framed-for instance, for benefits of screening, one could say that colorectal cancer mortality was reduced from $2 \%$ to $1 \%$ over 15 years or that the percentage of people who do not die from cancer increases from $98 \%$ to $99 \%$-influences peoples' decisions. We used only one method to present the benefits.

- Third, the first survey was based on a limited set of potential thresholds with large increments $(1,10,20$, or 30 prevented deaths or cancers). Smaller increments might have led to a different choice-and may have been one factor in the different choice of thresholds for FIT.

- Fourth, the panel made a single recommendation at the "break-even point" where benefits and harms are closely balanced. The panel could have chosen to make additional recommendations at a very low risk (where almost all would choose not to screen), or a very high risk (where almost all would choose screening). The available evidence suggests, however, that there may be those who would decline screening even with a very large benefit, and those who would choose screening even with a very small benefit.

cohort from a US registry. ${ }^{42728}$ The estimates from this cohort study are consistent with the best current evidence regarding serious harms from screening (see appendix 5). In the model, the harms are driven by the number of colonoscopies needed, and are of low certainty due to modelling of number of colonoscopies (see appendix 1 for full evidence summaries).

\section{Planned evaluation of harms by age}

Limited data exists addressing harms of screening by age. The gastrointestinal adverse events from colonoscopy probably increase with age, but the absolute risk is still 
very small in individuals above 75 years old. The panel therefore decided that these differences would not influence the recommendations (see appendix 5 for details).

\section{Colorectal cancer risk prediction}

A recent systematic review and an external validation study of colorectal cancer risk prediction models identified several prediction models, developed in different countries and with similar discrimination, as detailed in appendix 6. ${ }^{29} 30$ The QCancer was one of the best performing models for both men and women, with an area under the receiver operating curve (AUC) of 0.85 for women and 0.86 for men in the development cohort, ${ }^{31}$ and 0.66 for women and 0.70 for men in the external validation cohort. $^{29}$

The QCancer model was developed within a UK population and may overestimate or underestimate risk for individuals from other countries with different distributions of risk factors and/or incidence of colorectal cancer. We nevertheless suggest this model because it is available as an online calculator; includes only risk factors available in routine healthcare; has been validated in a population separate from the derivation population; has reasonable discriminatory ability; and has a good fit between predicted and observed outcomes (calibration). ${ }^{2931}$ In addition it is the only online risk calculator we know of that predicts risk over a 15 year time horizon.

\section{Understanding the recommendations}

If an individual's estimated 15-year risk of colorectal cancer is $3 \%$ or more, the panel suggests screening with any one of the four options; if the estimated risk is below 3\% the panel suggests no screening. These are weak recommendations, which means that in the context of shared decision making, some people with a risk of over $3 \%$ are likely to decline screening, and some with a risk under $3 \%$ will choose to screen.

- Our recommendations apply to asymptomatic adults aged 50-79 years with a life expectancy of at least 15 years.

- Our recommendations do not apply to people who

- Have previously been screened

- Have a history of polyps or colorectal cancer

- Have inflammatory bowel disease

- Have hereditary syndromes that increase the risk of colorectal cancer, such as Lynch syndrome and familial adenomatous polyposis.

Several factors influence individuals' decisions whether to be screened, even when they are presented with the same information:

- Variation in an individual's values and preferences

- A close balance of benefits versus harms and burdens (for example, for a baseline risk of 3\%, FIT every two years results in five fewer deaths from colorectal cancer per 1000 screened versus three gastrointestinal or cardiovascular adverse events and 246 needing at least one colonoscopy).

- The estimates of both benefits and harms are associated with considerable uncertainty, as is the estimate of an individual's risk over a 15 year time frame.
The panel did not recommend any of the four screening options over any other. Clinicians should support each individual to choose their most suitable option. These recommendations are based on full adherence to screening and all potential work-up and surveillance colonoscopies in a 15 year period. With full adherence the options have similar reductions in colorectal cancer mortality, but different reductions in colorectal cancer incidence. The tests also have different burdens and practical issues.

Some individuals may value a minimally invasive test such as FIT, and the possibility of invasive screening with colonoscopy might put them off screening altogether. Those who most value preventing colorectal cancer or avoiding repeated testing are likely to choose sigmoidoscopy or colonoscopy. Fig 3 presents practical issues key to the screening decision.

\section{How to estimate an individual's 15-year colorectal cancer risk}

We suggest the QCancer calculator for estimating the colorectal cancer risk (see main infographic). The calculator includes age, sex, ethnicity, smoking status, alcohol use, family history of gastrointestinal cancer, personal history of other cancers, diabetes, ulcerative colitis, colonic polyps, and body mass index. To minimise the likelihood of misinterpretation and to facilitate shared decision making, the ideal setting for using the calculator may be a consultation with a healthcare provider.

If the predicted risk for a particular individual is, for example, $3.0 \%$, the appropriate interpretation is: "In a group of 100 people with the same risk factors as you, 3 will develop colorectal cancer within the next 15 years.”

\section{As they age, people may revisit their decision}

The most important risk factor for colorectal cancer screening is age. After age 50, colorectal cancer risk increases by $0.5-1.5 \%$ every five years for most people. ${ }^{1314}$ This translates to an additional reduction in colorectal cancers of $0-2$ per 1000 screened individuals for FIT, and of 1-5 per 1000 for colonoscopy and sigmoidoscopy. The additional reduction in colorectal cancer mortality will be 1 per 1000 or smaller. Those who decide not to undertake screening but who think an additional benefit of this magnitude might change their decision, might consider reviewing their risk approximately every five years.

\section{Public health implications}

This guideline underlines that people need balanced information to decide whether they wish to screen for colorectal cancer, and public health efforts should focus on shared decision making for individuals who are eligible for screening. Many healthcare systems use the uptake of colorectal cancer screening as a performance indicator. ${ }^{32}{ }^{33}$ As many well informed individuals will choose to forego screening, discussion and information sharing on screening for colorectal cancer would be a better marker of care rather than uptake. 
PRACTICAL ISSUES

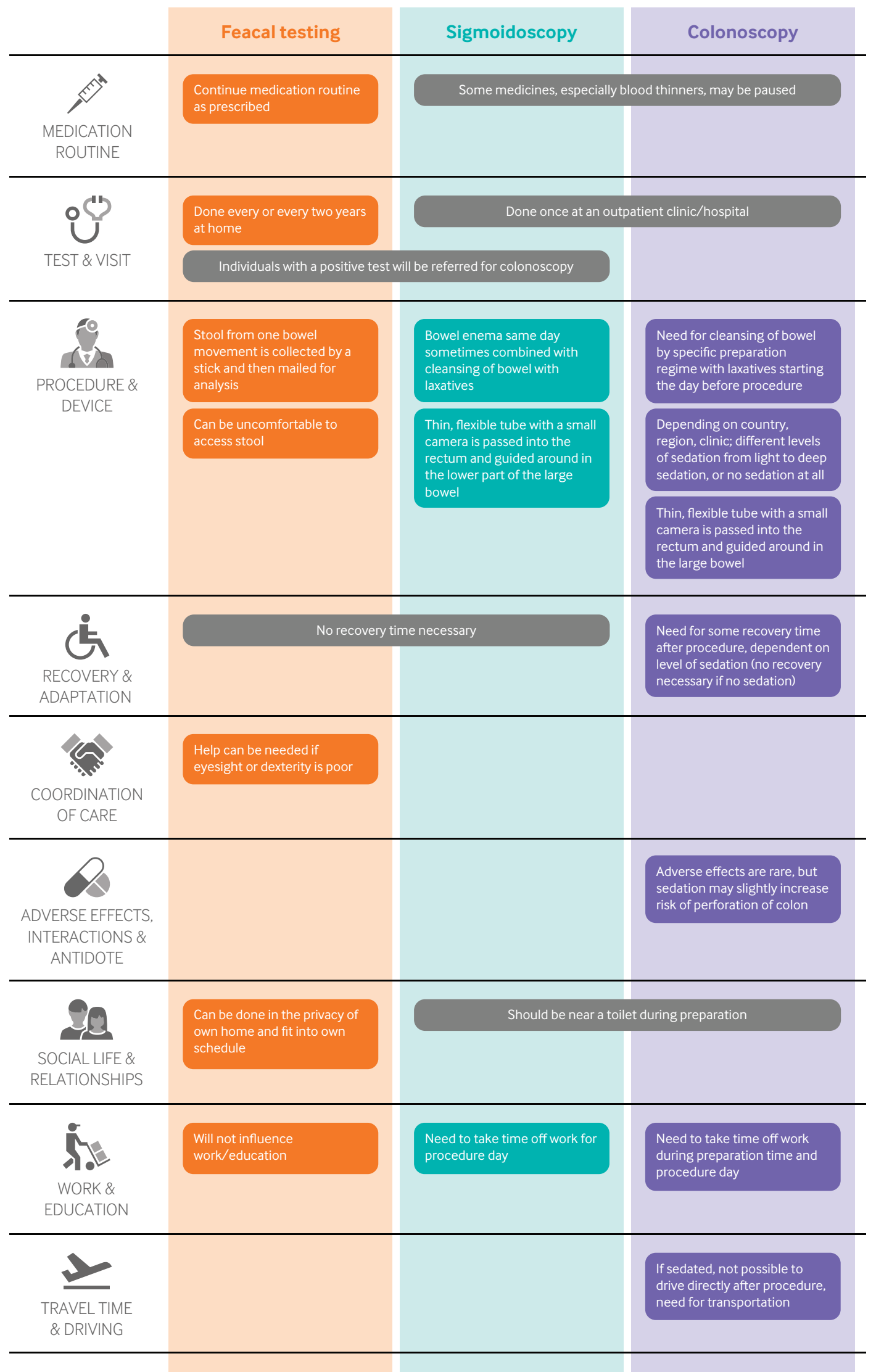




\section{EDUCATION INTO PRACTICE}

- How can you help individuals to make a choice about colorectal cancer screening based on the information you have read in this article?

- If your patients would like to leave the decision regarding screening in your hands, how would you handle the situation?

- What would you tell your colleagues about best practice for colorectal cancer screening?

\section{HOW PATIENTS WERE INVOLVED IN THE CREATION OF THIS \\ ARTICLE}

Three people who have experienced colorectal cancer screening were full panel members. These panel members identified important outcomes, participated in the teleconferences and email discussions on the evidence and recommendation. They also contributed to the identification of practical issues related to the decision of colorectal cancer screening and met all authorship criteria for the present article. We thank them for their time and contribution.

\section{Table $2 \mid$ New evidence which has emerged after initial publication \\ Implications for \\ New evidence Citation Findings recommendation(s) There are currently no updates to the article.}

\section{Uncertainty}

Only a few screening tests and intervals have been tested in randomised trials (once-only sigmoidoscopy and gFOBT every one or two years), but many different screening options are used in clinical practice. There are many uncertainties in terms of what is the most effective screening test or combination of tests, and at what age and interval they should be used. Some jurisdictions use combinations of screening tests; our guidelines do not address such combinations. We chose a 15 year timeframe and do not provide guidance beyond that point. It is uncertain whether there is additional benefit in continued FIT screening beyond 15 years or in a repeated sigmoidoscopy or colonoscopy before or after 15 years.

We found evidence that the relative reductions in incidence and mortality of colorectal cancer were smaller in women than in men after a single sigmoidoscopy, but the absolute effect differences were too small to warrant sexspecific recommendations. Whether the effects of other screening tests differ by sex is unknown.

The process of making these recommendations was challenging, often with opposing views in the panel. Particular challenges were the lack of randomised trials for colonoscopy and FIT (which made us rely on modelled estimates of low certainty for screening benefit) and the uncertainty in people's values and preferences.

Key research questions to inform decision makers and future guidelines include:

- What are the population's values and preferences regarding the magnitude of benefit needed to undergo screening, and the choice of screening test?

- What are the benefits and harms of colonoscopy and FIT screening, and do the effects differ for men and women?

\section{Updates to this article}

Table 2 shows evidence that has emerged since the publication of this article. As new evidence is published, a group will assess the new evidence and make a judgement on the extent it is expected to alter the recommendation.

We thank Hilde Iren Flaatten, senior librarian at the Medical Library, University of Oslo, for performing the literature searches. We thank Julia Hippisley-Cox and Stephen Hippisley-Cox for tailoring the QCancer calculator to the purpose of this guideline by adding the possibility of colorectal cancer risk estimation over 15 years, and for setting up a separate online calculator for colorectal cancer only. We thank Carla Berg-Nelson, who contributed as a patient partner with valuable feedback during the initial phase of this project.

Funding: This guideline was not funded.

Competing interests: All authors have completed the BMJ Rapid Recommendations interest disclosure form and a detailed, contextualised description of all disclosures is reported in appendix 2. As with all BMJ Rapid Recommendations, the executive team and The BMJ judged that no panel member had any financial conflict of interest. Professional and academic interests were minimised as much as possible, while maintaining necessary expertise on the panel to make fully informed decisions.

Disclaimer: Participation in the panel and authorship of this manuscript does not constitute organisational endorsement of the recommendations.

Transparency: L M Helsingen and G Guyatt affirm that the manuscript is an honest, accurate, and transparent account of the recommendation being reported; that no important aspects of the recommendation have been omitted; and that any discrepancies from the recommendation as planned have been explained.

1 Atkin W, Wooldrage K, Parkin DM, et al. Long term effects of once-only flexible sigmoidoscopy screening after 17 years of follow-up: the UK Flexible Sigmoidoscopy Screening randomised controlled trial. Lancet 2017;389:1299-311. 10.1016/S0140-6736(17)303963. pmid:28236467.

2 Holme $\varnothing$, Løberg M, Kalager M, et al. NORCCAP Study Groupt. Long-term effectiveness of sigmoidoscopy screening on colorectal cancer incidence and mortality in women and men: a randomized trial. Ann Intern Med 2018;168:775-82. 10.7326/M17-1441. pmid:29710125.

3 Miller EA, Pinsky PF, Schoen RE, Prorok PC, Church TR. Effect of flexible sigmoidoscopy screening on colorectal cancer incidence and mortality: long-term follow-up of the randomised US PLCO cancer screening trial. Lancet Gastroenterol Hepatol 2019;4:101-10. 10.1016/S2468 1253(18)30358-3. pmid:30502933.

4 Buskermolen M, Cenin DR, Helsingen LM, et al. Colorectal cancer screening with faecal immunochemical testing, sigmoidoscopy or colonoscopy: a microsimulation modelling study. BMJ 2019;367:15383. 10.1136/bmj.15383

5 Jodal HC, Helsingen LM, Anderson JC, et al. Colorectal cancer screening with faecal testing, sigmoidoscopy or colonoscopy: a systematic review and network meta-analysis. BMJ Open 2019;0:e032773. 10.1136 bmiopen-2019-032773.

6 Bray F, Ferlay J, Soerjomataram I, Siegel RL, Torre LA, Jemal A. Global cancer statistics 2018: GLOBOCAN estimates of incidence and mortality worldwide for 36 cancers in 185 countries. CA Cancer J Clin 2018;68:394-424. 10.3322/caac.21492. pmid:30207593.

7 Øines M, Helsingen LM, Bretthauer M, Emilsson L. Epidemiology and risk factors of colorectal polyps. Best Pract Res Clin Gastroenterol 2017;31:419-24. 10.1016/j.bpg.2017.06.004. pmid:28842051.

8 Bénard F, Barkun AN, Martel M, von Renteln D. Systematic review of colorectal cancer screening guidelines for average-risk adults: Summarizing the current global recommendations. World J Gastroenterol 2018:24:124-38. 10.3748/wig.v24.i1.124. pmid:29358889.

9 Ebell MH, Thai TN, Royalty KJ. Cancer screening recommendations: an international comparison of high income countries. Public Health Rev 2018;39:7. 10.1186/s40985-018-0080-0. pmid:29507820.

10 NHS. Bowel scope screening. https://www.nhs.uk/conditions/bowecancer-screening/bowel-scope-screening/.

11 Navarro M, Nicolas A, Ferrandez A, Lanas A. Colorectal cancer population screening programs worldwide in 2016: An update. World J Gastroentero 2017;23:3632-42. 10.3748/wig.v23.i20.3632. pmid:28611516.

12 Levin TR, Corley DA, Jensen CD, et al. Effects of organized colorectal cance screening on cancer incidence and mortality in a large community-based population. Gastroenterology 2018;155:1383-1391.e5. 10.1053/j. gastro.2018.07.017. pmid:30031768

13 Cancer Research UK. Bowel cancer incidence statistics. https://www. cancerresearchuk.org/health-professional/cancer-statistics/statistics-bycancer-type/bowel-cancer/inc\#heading-Zero.

14 Danckert B FJ, Engholm G, Hansen HL, et al. NORDCAN: Cancer incidence, mortality, prevalence and survival in the Nordic countries. Version 8.2. Association of the Nordic Cancer Registries. Danish Cancer Society. Available from http://www.ancr.nu. 
15 Lin JS, Piper MA, Perdue LA, et al. U.S. Preventive Services Task Force Evidence Syntheses, formerly Systematic Evidence Reviews. Screening for Colorectal Cancer: A Systematic Review for the US Preventive Services Task Force. Rockville (MD).Agency for Healthcare Research and Quality, 2016.

16 Blom J, Lowbeer C, Elfstrom KM, et al. Gender-specific cut-offs in colorectal cancer screening with FIT: increased compliance and equal positivity rate. J Med Screen 2019;26:92-7. 10.1177/0969141318804843. pmid:30336730.

17 Moss S, Mathews C, Day TJ, et al. Increased uptake and improved outcomes of bowel cancer screening with a faecal immunochemical test: results from a pilot study within the national screening programme in England. Gut 2017;66:1631-44. 10.1136/ gutjnl-2015-310691. pmid:27267903.

18 Guyatt GH, Oxman AD, Vist GE, et al. GRADE Working Group. GRADE: an emerging consensus on rating quality of evidence and strength of recommendations. BMJ 2008;336:924-6. 10.1136/ bmj.39489.470347.AD. pmid:18436948.

19 Siemieniuk RA, Agoritsas T, Macdonald H, Guyatt GH, Brandt L, Vandvik PO Introduction to BMJ Rapid Recommendations. BMJ 2016;354:15191. 10.1136/bmi.i5191. pmid:27680768.

20 Agoritsas T, Heen AF, Brandt L, et al. Decision aids that really promote shared decision making: the pace quickens. BMJ 2015;350:97624. 10.1136/bmj.g7624. pmid:25670178.

21 Alonso-Coello P, Oxman AD, Moberg J, et al. GRADE Working Group. GRADE Evidence to Decision (EtD) frameworks: a systematic and transparent approach to making well informed healthcare choices. 2: Clinical practice guidelines. BMJ 2016;353:i2089. 10.1136/bmj. i2089. pmid:27365494.

22 Hol L, de Bekker-Grob EW, van Dam L, et al. Preferences for colorectal cancer screening strategies: a discrete choice experiment $\mathrm{Br} / \mathrm{Cancer}$ 2010;102:972-80. 10.1038/sj.bjc.6605566. pmid:20197766.

23 Kistler CE, Hess TM, Howard K, et al. Older adults' preferences for colorectal cancer-screening test attributes and test choice. Patient Prefer Adherence 2015;9:1005-16.10.2147/ppa.S82203. pmid:26203233.

24 Bretthauer M, Kaminski MF, Løberg M, et al. Nordic-European Initiative on Colorectal Cancer (NordICC) Study Group. Populationbased colonoscopy screening for colorectal cancer: a randomized clinical trial. JAMA Intern Med 2016;176:894-902. 10.1001/ jamainternmed.2016.0960. pmid:27214731.

25 Quintero E, Castells A, Bujanda L, et al. COLONPREV Study Investigators. Colonoscopy versus fecal immunochemical testing in colorectalcancer screening. N Engl J Med 2012;366:697-706. 10.1056/ NEJMoa1108895. pmid:22356323.

26 Sun X, Briel M, Walter SD, Guyatt GH. Is a subgroup effect believable? Updating criteria to evaluate the credibility of subgroup analyses. BMJ 2010:340:c117. 10.1136/bmj.c117. pmid:20354011.

27 van Hees F, Zauber AG, Klabunde CN, Goede SL, LansdorpVogelaar I, van Ballegooijen M. The appropriateness of more intensive colonoscopy screening than recommended in Medicare beneficiaries: a modeling study. JAMA Intern Med 2014;174:1568-76.10.1001/ jamainternmed.2014.3889. pmid:25133641.

28 Warren IL, Klabunde CN, Mariotto AB et al. Adverse events after outpatient colonoscopy in the Medicare population. Ann Intern Med 2009;150:849-57, W152. 10.7326/0003-4819-150-12-200906160 00008 pmid: 19528563

29 Usher-Smith JA, Harshfield A, Saunders CL, et al. External validation of risk prediction models for incident colorectal cancer using UK Biobank. Br Cancer 2018;118:750-9. 10.1038/bjc.2017.463. pmid:29381683.

30 Usher-Smith JA, Walter FM, Emery JD, Win AK, Griffin SJ. Risk prediction models for colorectal cancer: a systematic review. Cancer PrevRes (Phila) 2016;9:13-26. 10.1158/1940-6207.CAPR-15 0274. pmid:26464100.
31 Hippisley-Cox J, Coupland C. Development and validation of risk prediction algorithms to estimate future risk of common cancers in men and women: prospective cohort study. BMJ Open 2015:5:e007825. 10.1136/bmjopen-2015-007825. pmid:25783428.

32 Healthy People.gov. C-16 Increase the proportion of adults who receive a colorectal cancer screening based on the most recent guidelines. 2019. https://www.healthypeople.gov/node/4054/data details\#revision history_header.

33 US Department of Veterans Affairs. Quality of care. https://www.va.gov/ QUALITYOFCARE/initiatives/compare/Prevention_Colorectal_Cancer_ Screening.asp.

Published by the BMJ Publishing Group Limited. For permission to use (where not already granted under a licence) please go to http://group. bmj.com/group/rights-licensing/permissions

${ }^{1}$ Clinical Effectiveness Research Group, Department of Transplantation Medicine, Oslo University Hospital, Oslo, Norway

${ }^{2}$ Clinical Effectiveness Research Group, Institute of Health and Society, University of Oslo, Oslo, Norway

${ }^{3}$ Frontier Science Foundation, Boston, Massachusetts, USA

${ }^{4}$ Institute of Health and Society, Faculty of Medicine, University of Oslo, Oslo, Norway

${ }^{5}$ Department of Medicine, Lovisenberg Diaconal Hospital, Oslo, Norway ${ }^{6}$ Division General Internal Medicine \& Division of Clinical Epidemiology, University Hospitals of Geneva, Geneva, Switzerland

${ }^{7}$ Department of Health Research Methods, Evidence, and Impact, McMaster University, Hamilton, Canada

${ }^{8}$ Veterans Affairs Medical Center, White River Junction, Vermont, USA

${ }^{9}$ The Geisel School of Medicine at Dartmouth, Hanover, New Hampshire, USA

${ }^{10}$ University of Connecticut Health Center, Farmington, USA

${ }^{11}$ Institute of Primary Health Care, University of Bern, Bern, Switzerland

${ }^{12}$ Center for Primary Care and Public Health, University of Lausanne, Lausanne, Switzerland

${ }^{13}$ Diakonhjemmet Hospital, Oslo, Norway

${ }^{14}$ Division of Gastroenterology, Department of Medicine, King Khalid University Hospital, King Saud University, Riyadh, Saudi Arabia.

${ }^{15}$ Division of Gastroenterology, The McGill University Health Center, Montreal General Hospital, McGill University, Montreal, Canada

${ }^{16}$ Division of Research, Kaiser Permanente, Oakland, California, USA

${ }^{17}$ Department of Gastroenterology, San Francisco Medical Center, California, USA

${ }^{18}$ Cochrane Consumers

${ }^{19}$ Society for Participatory Medicine, Boston, Massachusetts, USA

${ }^{20}$ Mighty Casey Media, LLC, Richmond, Virginia, USA

${ }^{21}$ Population Health and Health Policy Consultant, California, USA

${ }^{22}$ Patient Advisors Network, Founding Member, Canada

${ }^{23}$ American College of Physicians, Philadelphia, USA

${ }^{24}$ Department of Medicine, Innlandet Hospital Trust-division, Gjøvik, Norway

${ }^{25}$ The Primary Care Unit, Department of Public Health and Primary Care,

University of Cambridge, Cambridge, UK

${ }^{26}$ Department of Public Health, Erasmus MC University Medical Center

Rotterdam, Rotterdam, the Netherlands 